\title{
STUDY ON THE PREVALENCE AND ASSOCIATED FACTORS OF PERCEIVED STRESS ON COVID-19 AMONG HEALTHCARE PROVIDERS IN RUPANDEHI DISTRICT HEALTH INSTITUTIONS, WESTERN NEPAL
}

Sreya Paudyal, ${ }^{1}$ Sailaja Ghimire, ${ }^{2}$ Yudhisthir Raj Khadka, ${ }^{3}$ Manoj Dhungana ${ }^{4}$

\begin{abstract}
INTRODUCTION

Healthcare providers (HCPs) though stood as front-liners during the crisis situation were not themselves immune to the psychological consequences due to COVID-19. The present study aimed to find the prevalence of perceived stress on COVID-19 pandemic and its associated factors among health care providers in Rupandehi district health institutions.
\end{abstract}

\section{MATERIAL AND METHODS}

This cross- sectional study was conducted among the HCPs in the institutions of Rupandehi district in Western Nepal, from August to November, 2020. Total 126 subjects were included and probability sampling technique was applied for sample collection. After written consent from participants, socio-demographic data were collected and Perceived Stress Scale (PSS-10) was applied.

\section{RESULTS}

The study showed the prevalence of perceived stress in COVID-19 HCPs to be $65.1 \%$ considering score 20 as cut-off. Age, work place, precaution measures taken and staying with family were statistically significant with the perceived stress level $(p<0.05)$. Multivariate logistic regression showed perceived stress level had statistically significant association with precaution means and work place of HCPs. Healthcare providers who had unsatisfactory precaution means followed at work were 2.66 times more likely to have perceived stress as compared to satisfactory precaution means as adjusted odds ratio $(\mathrm{AOR})=2.66(1.09-6.51)$. Healthcare providers who stayed with family members were 2.28 times more likely to have perceived stress level as $\mathrm{AOR}=2.28(0.94-5.52)$.

\section{CONCLUSION}

The study showed increased prevalence of perceived stress among HCPs during the initial stage of COVID-19 pandemic in Nepal. Considering the findings, there is urgent need to develop and implement appropriate stress management and coping strategies to the target group.

\section{KEYWORDS}

COVID-19, Healthcare providers, Perceived stress.

1. Department of Psychiatry, Universal College of Medical Sciences, Bhairahawa, Nepal

2. Department of Obstetrics and Gynecology, Bhim Hospital, Bhairahawa, Nepal

3. Department of Orthopaedics Surgery, Lumbini Provincial Hospital, Butwal, Nepal

4. Department of Psychiatry, Devdaha Medical College, Devdaha, Nepal

DOI: https://doi.org/10.3126/jucms.v9i02.41991

For Correspondence

Dr. Sreya Paudyal

Department of Psychiatry

Universal college of Medical Sciences

Bhairahawa, Nepal

Email: drsreyapaudyal@gmail.com 


\section{INTRODUCTION}

The COVID-19 pandemic has created a crisis situation, and any such unexpected events or challenging situations can cause significant stress due to the feelings of uncertainty. Hence, perceived stress is the feelings that an individual has about how much stress they are under at a given point or over a given period. ${ }^{1,2}$ Healthcare providers (HCPs) who were in frontline for management of COVID-19 cases were in tremendous psychological distress besides physical stress. ${ }^{3,4}$

Significant and prolong exposure to stress may manifest itself in several outcomes including depression, anxiety, suicidal thoughts, loss of sleep, compromised immune function, and disturbed relationships. ${ }^{5-7}$ As other countries, Nepal was also least prepared for the pandemic as it did not have adequate testing kits, resource allocation, preventive measures, stepwise clinical response and management protocol to suspected or confirmed cases. ${ }^{5}$

The aim of this study was to assess the prevalence of perceived stress and its associated factors on COVID-19 among HCPs.

\section{MATERIAL AND METHODS}

This was an institutional based cross-sectional study conducted among the healthcare providers (HCPs) which included doctors, interns, nurses, health assistants, and pharmacists who were directly or indirectly involved in the care of patients with COVID-19 in different health institutions of Rupandehi district which is a metropolitan city in Western Nepal. Calculated sample size $=z^{2} p q / E^{2}=95$, prevalence of perceived stress $(p)=54 \%{ }^{8} q(1-p), z=1.96(95 \%$ confidence interval), $\mathrm{E}$ (allowable error) $=10 \%$.

A total of 126 healthcare workers from different hospitals meeting the inclusive criteria of being more than 18 years, and those consenting to participate were included in the study. Selection of centre were done randomly, as Rupandehi district has two Medical Colleges where general patients with COVID-19 and Non-COVID-19 were treated from which one was selected, only one provincial hospital and district hospital are present which were included, similarly private hospitals with bed more than 50 were included in the study. Each centre being considered as one stratum and by using proportionate stratified random sampling technique, samples were selected from each centre. One data collector from each hospital was selected who was trained on each item included in the study i.e., tools and objective of study. During data collection, supervision and follow up were made by investigator. The study was conducted during the increasing incidence of COVID-19 cases from mid-August to mid-November, 2020 after being approved by the ethical committee Universal College of Medical Sciences. (UCMS/IRC/060/20).
Data collection was carried out with a) semi-structured questionnaire to collect sociodemographic and clinical variables detail (age, gender, education, profession, marital status, type of family, work place, staying with family, following standard precautionary measure, chronic illness) and b) validated tool perceived stress scale-10 (PSS-10) was applied. ${ }^{9}$

\section{Perceived stress scale (PSS-10)}

The perceived stress scale (PSS) is the most widely used psychological instrument for measuring the perception of stress. The PSS-10 questionnaire had 10 statements and the respondents were asked to indicate their level of agreement using an ordinal scale $(0=$ Never; $1=$ Almost; $2=$ Sometimes; $3=$ Fairly often; $4=$ Very often). PSS -10 has a possible range of scores from 0 to 40 . More score indicates more stress and vice versa. The range of PSS scores were also divided into quartiles. The upper two and lower two quartiles were combined ( 20 being the operational cut off value for the upper bound) and were labelled as stressed and not-stressed respectively for this study. This cut off value was selected in accordance to a similar study from India. ${ }^{10}$ In other studies PSS-14 scale was used and similarly a score of 28 was considered as operational cut off. ${ }^{11,12}$

Data were coded and entered into Microsoft Excel sheet and analyzed using Statistical Package for Social Science (SPSS) version 16. Descriptive statistics like frequency, percentage were used to find the descriptive information of variables. In inferential statistics, Chi-square test was used to find the association between significant perceived stress level and sociodemographic variables. Further, multivariate logistic regression was used to find the net effect of significant variable in perceived stress level. Results were reported using crude and adjusted odds ratios (COR and AOR respectively) with corresponding $95 \%$ confidence intervals $(\mathrm{CI}) . p$ value less than 0.05 is considered as statistically significant.

\section{RESULTS}

A total 126 subjects were included in the present study, where $34.9 \%$ were male while $65.1 \%$ were female. About $54 \%$ of the study populations were age group 18-30 years, while only $7.9 \%$ were more than 60 years. In the study, $32.5 \%$ were nurses and postgraduate doctors. About $54.8 \%$ of participants were married, $63.5 \%$ of total were from nuclear family and $60.3 \%$ of healthcare providers stayed with their family members during this Covid-19 pandemic. As per the work place $43.7 \%$ were working in teaching hospital, $41.3 \%$ were working in district and provincial hospitals while only $12.7 \%$ were from private hospital and $2.4 \%$ included in the study were from primary health centre. Chronic illnesses like 
diabetes, hypertension, respiratory problems, heart disease were reported in $19 \%$ of study population. Most of the health workers $(70.6 \%)$ agreed on working with unsatisfactory precautionary measures with no proper personal protective equipment (PPE) sets.

The study showed that the prevalence of overall perceived stress in COVID-19 HCPs found to be $65.1 \%$ considering score 20 as cut-off. Out of the 126 subjects, 82 subjects had a PSS Score $\geq 20$ and hence were considered to be stressed. Age, work place, precaution measures taken and staying with family have a statistically significant association with the perceived stress level as $p<0.05$ (Table1). However, variables like gender, marital status, type of family of healthcare providers, education level, individual's profession and presence of chronic illness were not determinants of perceived stress.

Table 1. Association between the variables and perceived stress score

\begin{tabular}{|c|c|c|c|}
\hline Variables & & Frequency (\%) & $p$-value \\
\hline Age group & $\begin{array}{l}18-30 \text { years } \\
31-59 \text { years } \\
60 \text { years and more }\end{array}$ & $\begin{array}{l}68(54.0) \\
48(38.1) \\
10(7.9)\end{array}$ & 0.05 \\
\hline Gender & $\begin{array}{l}\text { Male } \\
\text { Female }\end{array}$ & $\begin{array}{l}44(34.9) \\
82(65.1)\end{array}$ & 0.154 \\
\hline Marital status & $\begin{array}{l}\text { Unmarried } \\
\text { Married } \\
\text { Widow }\end{array}$ & $\begin{array}{l}56(44.4)) \\
69(54.8) \\
1(0.8)\end{array}$ & 0.349 \\
\hline Family type & $\begin{array}{l}\text { Nuclear } \\
\text { Joint }\end{array}$ & $\begin{array}{l}80(63.5) \\
46(36.5)\end{array}$ & 0.127 \\
\hline Education & $\begin{array}{l}\text { Masters and above } \\
\text { Bachelors } \\
\text { Diploma }\end{array}$ & $\begin{array}{l}47(37.3) \\
46(36.5) \\
33(26.2)\end{array}$ & 0.594 \\
\hline Profession & $\begin{array}{l}\text { Postgraduate } \\
\text { Resident } \\
\text { House officer } \\
\text { Interns } \\
\text { Nurses } \\
\text { Pharmacist } \\
\text { Health Assistant }\end{array}$ & $\begin{array}{l}41(32.5) \\
8(6.3) \\
14(11.1) \\
8(6.3) \\
41(32.5) \\
5(4.0) \\
9(7.1)\end{array}$ & 0.458 \\
\hline Work place & $\begin{array}{l}\text { Teaching Hospital } \\
\text { Provincial/ District } \\
\text { Private Hospital } \\
\text { PHC }\end{array}$ & $\begin{array}{l}55(43.7) \\
152(41.3) \\
16(12.7) \\
3(2.4)\end{array}$ & 0.017 \\
\hline Precaution means & $\begin{array}{l}\text { Satisfactory } \\
\text { Unsatisfactory }\end{array}$ & $\begin{array}{l}37(29.4) \\
89(70.6)\end{array}$ & 0.037 \\
\hline Chronic illness & $\begin{array}{l}\text { No } \\
\text { Yes }\end{array}$ & $\begin{array}{l}24(19.0) \\
102(81.0)\end{array}$ & 0.108 \\
\hline Stay with family & $\begin{array}{l}\text { No } \\
\text { Yes }\end{array}$ & $\begin{array}{l}76(60.3) \\
50(39.7)\end{array}$ & 0.004 \\
\hline
\end{tabular}

Table 2. Multivariate logistic regression of variables with perceived stress score

\begin{tabular}{|c|c|c|c|c|c|}
\hline \multirow{2}{*}{\multicolumn{2}{|c|}{ Variables }} & \multicolumn{2}{|c|}{ Perceived stress } & \multirow{2}{*}{$\begin{array}{c}\text { Crude O.R } \\
(95 \% \text { C.I })\end{array}$} & \multirow{2}{*}{$\begin{array}{c}\text { Adjusted O.R } \\
(95 \% \text { C.I) }\end{array}$} \\
\hline & & $<20$ & $>\mathbf{2 0}$ & & \\
\hline \multirow[t]{2}{*}{ Gender } & Male & $19(43.2)$ & $25(56.8)$ & 1 & \\
\hline & Female & $25(30.5)$ & $57(69.5)$ & $1.73(0.87-3.70)$ & \\
\hline \multirow{3}{*}{ Age (years) } & $18-30$ & $21(30.9)$ & $47(69.1)$ & 1 & 1 \\
\hline & $31-59$ & $22(45.8)$ & $26(54.2)$ & $0.53(0.24-1.14)$ & $0.51(0.22-1.19)$ \\
\hline & $>60$ & $1(10)$ & $9(90)$ & $4.02(0.48-33.81)$ & $3.2(0.33-31.34)$ \\
\hline \multirow{3}{*}{ Education } & Masters & $19(40.4)$ & $28(59.6)$ & 1 & \\
\hline & Bachelors & $15(32.6)$ & $31(67.4)$ & $1.40(0.60-3.27)$ & \\
\hline & Diploma & $10(30.3)$ & $23(69.7)$ & $1.56(0.61-4.01)$ & \\
\hline \multirow{3}{*}{ Marital Status } & Unmarried & $18(32.1)$ & $38(67.9)$ & 1 & \\
\hline & Married & $25(36.2)$ & $44(63.8)$ & $0.83(0.40-1.76)$ & \\
\hline & Widowed & $1(100)$ & $0(0)$ & $\begin{array}{c}0.002 \\
(0.0005-0.001)\end{array}$ & \\
\hline \multirow{2}{*}{ Type of family } & Nuclear & $24(30)$ & $56(70)$ & 1 & \\
\hline & Joint & $20(43.5)$ & $26(56.5)$ & $0.56(0.26-1.18)$ & \\
\hline \multirow{7}{*}{ Profession } & Postgraduate & $15(36.6)$ & $26(63.4)$ & 1 & \\
\hline & Resident & $4(50)$ & $4(50)$ & $0.58(0.13-2.65)$ & \\
\hline & House officer & $3(21.4)$ & $11(78.6)$ & $2.11(0.51-8.80)$ & \\
\hline & Interns & $4(50)$ & $4(50)$ & $0.58(0.13-2.65)$ & \\
\hline & Nurses & $11(26.8)$ & $30(73.2)$ & $1.57(0.61-4.02)$ & \\
\hline & Pharmacist & $3(60)$ & $2(40)$ & $0.38(0.06-2.57)$ & \\
\hline & Health assistant & $4(44.4)$ & $5(55.6)$ & $0.72(0.17-3.11)$ & \\
\hline \multirow{4}{*}{ Work Place } & Teaching Hos. & $25(45.5)$ & $30(54.5)$ & 1 & 1 \\
\hline & P/District Hos. & $10(19.2)$ & $42(80.8)$ & $3.5(1.47-8.36)$ & $3.43(1.34-8.77)^{*}$ \\
\hline & Private Hospital & $7(43.8)$ & $9(56.2)$ & $1.07(0.35-3.29)$ & $1.67(0.49-5.71)$ \\
\hline & $\mathrm{PHC}$ & $2(66.7)$ & $1(33.3)$ & $0.42(0.04-4.87)$ & $0.41(0.03-5.30)$ \\
\hline \multirow{2}{*}{$\begin{array}{c}\text { Precaution } \\
\text { means }\end{array}$} & Satisfactory & $18(48.6)$ & $19(51.4)$ & 1 & 1 \\
\hline & Unsatisfactory & $26(29.2)$ & $6(70.8)$ & $2.30(1.04-5.06)$ & $2.66(1.09-6.51)^{*}$ \\
\hline \multirow{2}{*}{ Chronic Illness } & No & $39(38.2)$ & $63(61.8)$ & 1 & \\
\hline & Yes & $5(20.8)$ & $19(79.2)$ & $0.42(0.15-1.23)$ & \\
\hline \multirow{2}{*}{$\begin{array}{c}\text { Stay with } \\
\text { family }\end{array}$} & No & $25(50)$ & $25(50)$ & 1 & 1 \\
\hline & Yes & $19(25)$ & $57(75)$ & $3.0(1.40-6.41)$ & $2.28(0.94-5.52)$ \\
\hline
\end{tabular}

O. $\mathrm{R}=$ Odds ratio, $\mathrm{C} . \mathrm{I}=$ Confidence interval

Variables found to be associated in bivariate analysis were further entered into the multivariate logistic regression model for adjusting confounding factors. Age group 31-59 years were $49 \%$ less [adjusted OR $\{$ AOR $\}=0.51(0.22-1.19)$ ] likely to have perceived stress level as compared age group 18-30 years, since Adjusted OR is less than 1 (i.e. 0.51), so the likelihood of having the outcome is expressed as (1-0.51) $\mathrm{x}$ $100 \%$ less, and age group $>60$ years were 3.2 times more likely to have perceived stress level as compared to age group 18-30 years [adjusted $\mathrm{OR}=3.2(0.33-31.34)]$. Health workers who worked in District Hospital were 3.43 times more likely to have perceived stress level [adjusted OR=3.43 (1.34-8.77)], health workers who worked in private hospital were 1.07 times more likely to have perceived stress level [adjusted $\mathrm{OR}=1.67(0.49-5.71)]$ and health workers who worked in PHC were $59 \%$ less likely to have perceived stress level [Adjusted $\mathrm{OR}=0.41(0.03-5.30)]$ as compared health workers who worked in teaching hospital. Health workers who had unsatisfactory precaution means were 2.66 times more likely 
to have perceived stress level as compared to satisfactory precaution mean [adjusted OR=2.66 (1.09-6.51)]. Health workers who stayed with family members were 2.28 times more likely to have perceived stress level [adjusted $\mathrm{OR}=2.28$ (0.94-5.52)]. Multivariate logistic regression showed that perceived stress level had statistically significant association with precaution means and work place of health workers (Table 2).

\section{DISCUSSION}

The study showed that the prevalence of overall perceived stress in COVID - 19 HCPs found to be $65.1 \%$. Several studies done at different places showed similar results, study done at Ethiopia showed $61.8 \%$ and Ghana reported $64 \%$ of healthcare professionals had moderate stress. ${ }^{13,14}$ The result showed higher perceived stress which might be due to low perceived preparedness to respond to the COVID-19 pandemic which was itself associated with stress among HCPs. ${ }^{14}$ However, comparing the prevalence to some other studies done by Wang et al (53.8\%) and Yigrem Ali et al $(51.6 \%)$, the current prevalence of perceived stress is slight high. ${ }^{8,15}$

In the present study, majority $65.1 \%$ of the participants were females, most of the participants 54\% were of age group 18-30 years and majority $54.8 \%$ were married. A study conducted in China revealed similar findings with the majority of respondents being female $67.3 \%$, in the age range of 21.4 to 30.8 years $53.1 \%$, and married were $76.4 \%{ }^{8}$. The odds of having perceived stress on COVID-19 among health workers who were $>60$ years was 3.2 times more likely compared to those in the age range of 18-30 years of respondents. Advance age is considered as risk factors for adverse outcome in COVID-19. Several studies showed that adults over 65 years of age represent $80 \%$ of hospitalizations and have a 23 -fold greater risk of death than those under $65 .^{16}$ This might be due to the impact of the co-morbidities, immune system capacity, and poor coping strategies elders experience with aging and knowing this fact in medical professional could be possible reason for high perceived stress score in age group $>60$ years.

Another interesting finding in the study was that age groups $31-59$ years were $49 \%$ less likely to have perceived stress level as compared younger age group 18-30 years. It showed that young HCPs (medical officers, interns, junior residents, nurses) had more perceived stress. The previous studies have also found significantly high stress among trainee doctors, younger doctors and nurses. ${ }^{17-19}$ Resident doctors, trainees and nurses are required to had closer interaction with patient as compared to senior faculty members who have more of supervisory roles.

Healthcare providers who stayed with family members were
2.28 times more likely to have perceived stress level than those staying alone. Those staying with families had higher perceived stress possibly with risk of transmitting them. Safety of family members were seen as major concern to healthcare providers in many other studies. Urooj et al found that $79.7 \%$ of doctors are afraid of infecting family members and $28.8 \%$ are afraid of becoming a carrier to others. ${ }^{20}$

As per the work place $43.7 \%$ were working in teaching hospital, while $41.3 \%$ were working in district and provincial hospital which were designated as COVID-19 hospitals by Government of Nepal for management of COVID-19 patients until later when all the medical colleges and private sectors were engaged in COVID-19 response. The finding shows that the health workers who worked in provincial/district hospital were 3.43 times more likely to have perceived stress compared to health workers who worked in teaching hospital. Further, health workers working in PHC were 59\% less likely to have perceived stress level as compared to those working in medical college. As the result showed, health workers working in Government hospitals had perceived stress greater than those working in medical college, one of the possible reasons for that could be as mentioned above Provincial/district hospitals were designated as COVID-19 Hospital by Ministry of Health and Population (MoHP) at first place. These hospitals were allotted for screening, testing, treating and referring the COVID-19 cases during first wave until others were involved and this study was conducted during that period. So the health workers working at those place possibly were more stressed compared to others.

Chronic illnesses like diabetes, hypertension, respiratory problems, heart disease were reported in $19 \%$ of study population. Presence or absence of chronic illness was not predictors of perceived stress in the present study. Most of the health workers $(70.6 \%)$ agreed on working with unsatisfactory precautionary measures with no proper personal protective equipment (PPE) sets. The study showed that health workers who were unable to follow satisfactory safety measures during management and care of COVID-19 patients because of unavailability and shortage of necessary personal protective gears at their respective workplaces were 2.66 times more likely to have perceived stress level. Similar result was shown by other studies, $70 \%-85 \%$ of health care professionals responded that the availability of PPE in their working health institution was not adequate. ${ }^{13,21}$ Multivariate logistic regression analysis showed that the work place of the HCPs and availability/ use of precautionary means while on duty were the main predictors of perceived stress.

Discussing the limitation of the present study, the study was conducted during the early phase of pandemic and thus the other stressful situations of HCPs existing before the 
pandemic were not ruled out which might bias the current result. The sample size was small in the study. Respondent bias might be there as tool used was self-reported.

\section{CONCLUSION}

Healthcare providers have faced considerable perceived stress during the pandemic. Variables like age, staying with family members during pandemic, precautionary measures taken during patient care and work place of HCPs has significant association with perceived stress. The degree to which we protect the physical health and mental wellbeing of HCPs will shape the pandemic. Management of stress among healthcare providers should be one of the priority during this global pandemic situation.

\section{ACKNOWLEDGEMENTS}

The authors would like to thank all the anonymous participants for filling out the questionnaire in the study.

\section{CONFLICT OF INTEREST}

\section{None}

\section{REFERENCES}

1. Phillips AC. Perceived stress. Encyclopedia of Behavioral Medicine. Springer, New York, NY. 2013;1453-1454.

2. Lazarus RS, Folkman S. Stress, coping and adaptation. New York: Springer, 1984.

3. Burbeck R, Coomber S, Robinson SM, Todd C. Occupational stress in consultants in accident and emergency medicine: a national survey of levels of stress at work. Emerg Med J. 2002 May;19(3):234-8.

4. Spoorthy MS, Pratapa SK, Mahant S. Mental health problems faced by healthcare workers due to the COVID19 pandemic-A review. Asian Journal of Psychiatry. 2020 Jun;51:102119.

5. United Nation Nepal, COVID-19 Nepal: Preparedness and response plan (NPRP), NPRP for COVID-19. April 2020.

6. JLM Lindo, McCaw-Binns A, J La Grenade, M Jackson, D Eldemire-Shearer. Mental well-being of doctors and nurses in two hospitals in Kingston, Jamaica. West Indian Med J. 2006 June;55(3):153-9.

7. Felton JS. Burnout as a clinical entity-its importance in healthcare workers. Occup Med (Lond). 1998;48:237-50.

8. Wang C, Pan R, Wan X, et al. Immediate psychological responses and associated factors during the initial stage of the 2019 coronavirus disease (COVID-19) epidemic among the general population in China. International Journal of Environmental Research and Public Health. 2020;17:1729-31

9. Cohen S, Lamarch T, Mermelstein R. A global measure of perceived stress. J Health Soc Behav. 1983;24(4):385-96.

10. Sathiya N, Ruwaidha R, Nusrath FS, Fathima F, Gomathy T, Shailendra HK. Perceived stress levels and its sources among Doctors and nurses working in a Tertiary Care Teaching Hospital, Kancheepuram, Tamil Nadu. Ntl J Community Med. 2016;7(7):603-608.

11. Brahmbhatt KR, Nadeera VP,Prasanna KS, Jayram S Perceived stress and sources of stress among medical undergraduates in a private Medical College in Mangalore, India. Int $\mathrm{J}$ of Biomed and Adv Res. 2013;4(2):129-136

12. Shah M, Hasan S, Malik S, Sreeramareddy CT. Perceived stress, sources and severity of stress among medical undergraduates in a Pakistani Medical School. BMC Medical Education. 2010 Dec;10(1):1-8.

13. Teshome A, Shegaze M, Glagn M, Getie A, Tekabe B, Getahun D, Kanko T, Getachew T, Yenesew N, Meskele S, Tolosie K. Perceived stress and associated factors among health care professionals working in the context of COVID-19 pandemic in public health institutions of Southern Ethiopia 2020. PloS one. 2021 Jun 10;16(6):e0252809.

14. Afulani PA, Gyamerah AO, Nutor JJ, Laar A, Aborigo RA, Malechi H, Sterling M, Awoonor-Williams JK. Inadequate preparedness for response to COVID-19 is associated with stress and burnout among healthcare workers in Ghana. PloS One. 2021; 16(4):e0250294.

15. Chekole YA, Yimer Minaye S, Mekonnen Abate S, Mekuriaw B. Perceived stress and its associated factors during COVID-19 among healthcare providers in Ethiopia: a cross-sectional study. Advances in Public Health. 2020 Oct;2020: Article ID 5036861.

16. Mueller AL, McNamara MS, Sinclair DA. Why does COVID-19 disproportionately affect older people? Aging (Albany NY). 2020;12(10):9959-9981.

17. Garg R, Singla A, Garg J. Perceived stress among doctors working in a dedicated COVID-19 hospital in North India. Indian J Med Sci. 2021 May:73(2):155-8

18. Abdulah DM, Mohammed AA. The consequences of the COVID-19 pandemic on perceived stress in clinical practice: experience of doctors in Iraqi Kurdistan. Rom J of Intern Med. 2020 Dec; 58(4):219-27.

19. Elbay RY, Kurtulmuş A, Arpacıoğlu S, Karadere E. Depression, anxiety, stress levels of physicians and associated factors in Covid-19 pandemics. Psychiatry Research. 2020 Aug;290:e113130.

20. Urooj U, Ansari A, Siraj A. Expectations, fears and perceptions of doctors during COVID-19 pandemic. Pak J Med Sci. 2020;36 (COVID19-S4):S37-S42.

21. Martin-Delgado J, Viteri E, Mula A, Serpa P, Pacheco G, Prada D, Campos de Andrade Lourenção D, Campos Pavan Baptista P, Ramirez G, Mira JJ. Availability of personal protective equipment and diagnostic and treatment facilities for healthcare workers involved in COVID-19 care: A cross-sectional study in Brazil, Colombia, and Ecuador. PloS one. 2020 Nov 11;15(11) :e0242185. 